\title{
Scaling maximal oxygen uptake to predict cycling time-trial performance in the field: a non-linear approach
}

\begin{abstract}
The purpose of the present article is to identify the most appropriate method of scaling $\dot{\mathrm{V}}_{\mathrm{O}_{2} \text { max }}$ for differences in body mass when assessing the energy cost of time-trial cycling. The data from three time-trial cycling studies were analysed $(N=79)$ using a proportional power-function ANCOVA model. The maximum oxygen uptake-to-mass ratio found to predict cycling speed was $\dot{\mathrm{V}}_{\mathrm{O}_{2} \max }(m)^{-0.32}$, precisely the same as that derived by Swain for sub-maximal cycling speeds $(10,15$ and $20 \mathrm{mph}$ ). The analysis was also able to confirm a proportional curvilinear association between cycling speed and energy cost, given by $\left(\dot{\mathrm{V}}_{\mathrm{O}_{2} \text { max }}(m)^{-0.32}\right)^{0.41}$. The model predicts, for example, that for a male cyclist $(72 \mathrm{~kg})$ to increase his average speed from $30 \mathrm{~km} \mathrm{~h}^{-1}$ to $35 \mathrm{~km} \mathrm{~h}^{-1}$, he would require an increase in $\dot{\mathrm{V}}_{\mathrm{O}_{2} \max }$ from $2.361 \mathrm{~min}^{-1}$ to $3.441 \mathrm{~min}^{-1}$, an increase of $1.081 \mathrm{~min}^{-1}$. In contrast, for the cyclist to increase his mean speed from $40 \mathrm{~km} \mathrm{~h}^{-1}$ to $45 \mathrm{~km} \mathrm{~h}^{-1}$, he would require a greater increase in $\dot{\mathrm{V}}_{\mathrm{O}_{2} \max }$ from $4.771 \mathrm{~min}^{-1}$ to $6.361 \mathrm{~min}^{-1}$, i.e. an increase of $1.591 \mathrm{~min}^{-1}$. The model is also able to accommodate other determinants of time-
\end{abstract}

\section{A. M. Nevill · S. A. Jobson}

Research Institute of Healthcare Sciences, University of Wolverhampton, Walsall, West Midlands, England

G. S. Palmer

Sportstest Ltd, Silver End Business Park, Brierley Hill,

West Midlands, England

T. S. Olds

Centre for Applied Anthropometry,

School of Health Sciences,

The University of South Australia, Underdale, South Australia

A. M. Nevill $(\bowtie)$

School of Sport, Performing Arts and Leisure, University of Wolverhampton, Gorway Road,

Walsall, WS1 3BD, England

E-mail: a.m.nevill@wlv.ac.uk

Tel.: + 44-1902-322838

Fax: $+44-1902-322898$ trial cycling, e.g. the benefit of cycling with a side wind (5\% faster) compared with facing a predominatly head/ tail wind $(P<0.05)$. Future research could explore whether the same scaling approach could be applied to, for example, alternative measures of recording power output to improve the prediction of time-trial cycling performance.

Keywords Power function - Proportional allometric model $\cdot$ Cycling speed $\cdot$ Body mass $\cdot$ Wind resistance

\section{Introduction}

There is a considerable body of knowledge investigating the energy cost of running in both adults (Margaria et al. 1963; Dill 1965; Nevill et al. 1992) and children (Nevill et al. 2004). Indeed, when investigating a group of recreationally active adults, men $(N=112)$ and women $(N=92)$, Nevill et al. (1992) were able to confirm that using both $\dot{\mathrm{V}}_{\mathrm{O}_{2} \max } 1 \mathrm{~min}^{-1}$ and body mass $(m)$ as predictor variables, the best predictor of $5-\mathrm{km}$ running performance $\left(\mathrm{m} \mathrm{s}^{-1}\right)$ was,

Run speed $\left(\mathrm{m} \mathrm{s}^{-1}\right)=84.3\left(\dot{\mathrm{V}}_{\mathrm{O}_{2} \max }\right)^{1.01}(m)^{-1.03}$.

With both exponents close to unity but with opposite signs, the model suggests that the energy cost of $5-\mathrm{km}$ run speeds was almost exactly proportional to (and a linear relationship with) the traditional ratio standard maximum oxygen uptake $\left(1 \mathrm{~min}^{-1}\right)$ divided by body mass $(\mathrm{kg})$ or $\left(\mathrm{ml} \mathrm{kg}^{-1} \mathrm{~min}^{-1}\right)$. A similar result was obtained when investigating the energy cost of running for 12-year-old boys (Nevill et al. 2004). The authors confirmed the best predictor of boys' 1-mile run speed was the traditional ratio standard, maximum oxygen uptake $\left(\mathrm{ml} \mathrm{kg}{ }^{-1} \min ^{-1}\right)$.

However, relatively little is known about the energy requirements of other sporting events that are weight supported, such as time-trial cycling, wheel-chair 
racing, rowing or canoeing. Clearly, further research is required to clarify whether the same linear relationship and body size denominator component of $\dot{\mathrm{V}}_{\mathrm{O}_{2} \max }$ as observed in running, is likely to be appropriate when predicting sporting performance in weight-supported events.

Swain (1994), when investigating the energy cost of cycling over relatively level ground at sub-maximal speeds (20,15 and $10 \mathrm{mph}$ ), was able to estimate (using a re-analysis of data from Swain et al. (1987)) that the mass exponent for oxygen consumption was only 0.32 , considerably less than the $2 / 3$ value expected on the basis of a surface area law. A similar mass exponent (0.31) was obtained when Swain (1994) re-analysed data originally published in McCole et al. (1990). Padilla et al. (1999) confirmed the utility of scaling maximal power output $\left(W_{\max }\right.$ ) by dividing $W_{\max }$ by $m^{0.32}$ as the most appropriate method of identifying level/flat cycling ability among a group of professional cyclists. Heil (2001) was also able to provide a theoretical explanation for the mass exponent (0.32) based on projected frontal area.

These findings suggest that the energy cost of submaximal cycling is the oxygen-to-mass ratio, $\dot{\mathrm{V}}_{\mathrm{O}_{2}}(m)^{-1 / 3}$. However, what is not clear is whether this relationship is likely to be the same for sub-maximal and maximal speeds (i.e. cycling at speeds close to $\left.\dot{\mathrm{V}}_{\mathrm{O}_{2} \max }\right)$. Indeed, given that the primary resistance to movement whilst cycling is air resistance, is this relationship between cycling speed and $\dot{\mathrm{V}}_{\mathrm{O}_{2}}(m)^{-1 / 3}$ likely to be linear or curvilinear? Pugh (1974) was able to confirm using polynomial regression that a curvilinear relationship exists between cycling speed and both $\dot{\mathrm{V}}_{\mathrm{O}_{2} \max }\left(1 \mathrm{~min}^{-1}\right)$ and $\dot{\mathrm{V}}_{\mathrm{O}_{2} \max }\left(\mathrm{ml} \mathrm{kg}^{-1} \mathrm{~min}^{-1}\right)$. Unfortunately, the polynomial regression methods adopted by Pugh were unable to explore whether either method of recoding oxygen consumption was optimal when predicting cycling speed performance. The author also fails to report details, e.g. the order of the fitted polynomial.

Hence, the purpose of the present article is to identify the most appropriate model to describe and scale/normalise $\dot{\mathrm{V}}_{\mathrm{O}_{2} \max }$ (for differences in body mass) when assessing the energy cost of maximal time-trial cycling performance on level ground. Given that the primary resistance to movement whilst cycling is proportional to air resistance, we shall adopt a proportional allometric or power-function model to predict cycling speed that will not only assess the most appropriate oxygen-tomass ratio but will also accommodate the anticipated proportional curvilinear model associated with timetrial cycling speed. This will be achieved using the data from three studies. Study 1 consists of previously unpublished data collected from five time-trial events conducted in the West Midlands, UK during 2004. The data from two other studies (see Olds et al. 1995; Coyle et al. 1991) will be used to support further the findings from study 1 .

\section{Methods}

\section{Study 1}

\section{Subjects}

Twenty-three male cyclists were recruited from local cycling clubs to participate in this investigation (subject characteristics presented in Table 1). All subjects had previous experience of laboratory-based testing and competitive road time-trials. This study was approved by the Ethics Committee for the School of Sport, Performing Arts and Leisure at the University of Wolverhampton. Prior to participation in the investigation, subjects were fully informed of the nature and risks of the study, before providing written consent. Subjects were competitive but non-elite cyclists.

\section{Testing schedule}

Each subject visited the laboratory for a 2-h test session to determine subject characteristics. On a separate occasion, subjects performed a competitive 25-mile road time-trial. The laboratory session and the time-trial event were completed in a random order separated by no more than 10 days during the months of May, June and July.

\section{Laboratory testing}

On arrival at the laboratory, an anthropometric assessment of each subject was performed. Measurements were made by an ISAK qualified practitioner in accordance with procedures recommended by the International Society for the Advancement of Kinanthropometry (ISAK 2001). Participants then completed a progressive, incremental exercise test to exhaustion on a Kingcycle air-braked cycle ergometer (Kingcycle Ltd., High Wycombe, Buckinghamshire, UK). This system, which has previously been described in full (Palmer et al. 1996), allows the subject to exercise on their own bike against a resistance comparable to that of riding on the road. This system has been shown to be both valid and reliable during 20-km, 40-km (Palmer et al. 1996), and max-test protocols (Keen et al. 1991).

Following standardised calibration procedures (Palmer et al. 1996), subjects carried out a warm-up at a self-selected intensity for $10 \mathrm{~min}$. Immediately following this, the maximal test was initiated at a workload of 150-200 W. Thereafter, workload increased at a ramp rate of $20 \mathrm{~W} \mathrm{~min}{ }^{-1}$ ( $1 \mathrm{~W}$ every $\left.3 \mathrm{~s}\right)$. The test was terminated when the subject could no longer maintain the specified workload, despite strong verbal encouragement, given by the same investigator during all maximal trials. 
For the duration of the maximal test protocol, respiratory gases were recorded on a breath-by-breath basis using an Oxycon Pro automated gas analysis system (Erich Jaeger [UK] Ltd., Market Harborough, Leicestershire, UK). The Oxycon system was calibrated prior to use according to the manufacturers guidelines, using a known calibration gas and a 3-1 syringe (SensorMedics, Yorba Linda, CA, USA). $\dot{\mathrm{V}}_{\mathrm{O}_{2} \max }$ was identified as a plateau in $\dot{\mathrm{V}}_{\mathrm{O}_{2}}$ and/or as a respiratory exchange ratio $>1.10$. Maximal oxygen consumption $\left(\dot{\mathrm{V}}_{\mathrm{O}_{2} \max }\right)$ was calculated as the highest average oxygen consumption over a 60 -s period.

\section{Road time-trials}

Subjects competed in one of five competitive 25-mile time-trial events, each being carried out on a relatively flat course and according to the regulations of the Road Time Trials Council (RTTC 2004). Data collection was organised so as to minimise the disturbance to the normal race routine. Temperature, relative humidity and barometric pressure were measured on site every 510 min. Following a warm-up of self-selected duration and intensity, all subjects used geared road bicycles fitted with 'aero' bars, to complete the race distance as quickly as possible. No drafting was permitted. For the completed 25-mile time-trial, total time (min:s), average speed $\left(\mathrm{km} \mathrm{h}^{-1}\right)$ and average heart rate (beats $\left.\mathrm{min}^{-1}\right)$ were calculated.

The methods used during studies 2 and 3 have previously been described in detail (see Olds et al. (1995) and Coyle et al. (1991), respectively). As such, the following sections provide only a brief summary.

\section{Study 2}

\section{Subjects}

Thirty-two male and nine female individuals (subject characteristics presented in Table 1), with subjects being classified/grouped as either club or national standard.

\section{Laboratory testing}

A geared, wind-braked cycle ergometer with components and configuration similar to a racing bicycle was used for the incremental $\dot{\mathrm{V}}_{\mathrm{O}_{2} \max }$ test. From an initial workload of 77-149 W, the work rate was increased 30$50 \mathrm{~W}$ at 2-min intervals. Gas analysis was performed on a breath-by-breath basis (Ametek OCM2 metabolic assessment system, Applied Electrochemistry, Pittsburgh, PA, USA), with data averaged over $30 \mathrm{~s}$. The test was terminated when $\dot{\mathrm{V}}_{\mathrm{O}_{2} \max }$ was identified [an oxygen uptake $\left(\dot{\mathrm{V}}_{\mathrm{O}_{2}}\right.$ ) difference of $<0.151 \mathrm{~min}^{-1}$ for successive work rates] or at the point at which the required pedal cadence (95-105 rpm) could no longer be maintained. $\dot{\mathrm{V}}_{\mathrm{O}_{2} \max }$ was taken as the highest average $\dot{\mathrm{V}}_{\mathrm{O}_{2}}$.

\section{Road time-trials}

All subjects completed a $26-\mathrm{km}$ time-trial, comprising four lengths of a flat $6.5-\mathrm{km}$ sealed bitumen course. All riders used geared road bicycles to cover the distance as quickly as possible. Drafting was not permitted. Wind direction was noted for each time-trial as being either predominantly a head/tail wind or a side wind.

\section{Study 3}

\section{Subjects}

Fifteen male competitive USCF category 1 or 2 cyclists were recruited for this study (subject characteristics presented in Table 1). Subjects whose recent best time for a $40-\mathrm{km}$ time-trial was faster than $56 \mathrm{~min}$ were identified as group 1 ('elite-national class'). Subjects with slower performances were placed in group 2 ('good-state class').

\section{Laboratory testing}

The body composition of each subject was determined by hydrostatic weighing, whilst $\dot{\mathrm{V}}_{\mathrm{O}_{2} \max }$ was determined during a laboratory cycle test. Specifically, subjects used a Monark cycle ergometer to complete an incremental protocol lasting between $8 \mathrm{~min}$ and $10 \mathrm{~min}$, the work rate being increased at 2-min intervals. Expired gases were continuously sampled from a mixing chamber and analysed for $\mathrm{O}_{2}$ (Applied Electrochemistry S3A) and $\mathrm{CO}_{2}$ (Beckman LB-2). Inspired air volumes were measured using a dry gas meter (Parkinson-Cowan CD4). These instruments were interfaced with an Apple IIe computer, which calculated $\dot{\mathrm{V}}_{\mathrm{O}_{2}}$ every $30 \mathrm{~s}$.

\section{Road time-trials}

The recent best time for each subject during a flat $40-\mathrm{km}$ road time-trial was recorded.

\section{Statistical methods}

Box and Cox (1964), Nevill et al. (1992) and more recently Ingham et al. (2002), recognised the need to record performance time as average speed (i.e. using the inverse transformation) to be more symmetric, normally distributed and be more linearly related to other variables, such as $\dot{\mathrm{V}}_{\mathrm{O}_{2} \max }$. For this reason, cycling performance times were converted to average time-trial speeds $\left(\mathrm{km} \mathrm{h}^{-1}\right)$.

In order to establish the most appropriate method of scaling/normalising $\dot{\mathrm{V}}_{\mathrm{O}_{2} \max }$ to best reflect cycling speed, the following power-function model (originally adopted by Nevill et al. (1992)) was used to explore the optimal relationship between cycle speed, $\dot{\mathrm{V}}_{\mathrm{O}_{2} \max }$ and body mass $(m)$, 
Table 1 Subject physical characteristics

\begin{tabular}{llllllll}
\hline & $N$ & $\begin{array}{l}\text { Age } \\
(\text { year })\end{array}$ & $\pm \mathrm{SD}$ & $\begin{array}{l}\text { Body mass } \\
(\mathrm{kg})\end{array}$ & $\pm \mathrm{SD}$ & $\dot{\mathrm{V}}_{\mathrm{O}_{2} \max }\left(1 \mathrm{~min}^{-1}\right)$ & $\pm \mathrm{SD}$ \\
\hline $\begin{array}{c}\text { Study } 1 \\
\text { Male }\end{array}$ & 23 & 41.3 & 10.9 & 78.0 & 9.4 & 4.29 & \\
$\begin{array}{c}\text { Study 2 } \\
\text { Male }\end{array}$ & 32 & 27.3 & 7.2 & 73.7 & 7.6 & 4.90 & 0.55 \\
$\begin{array}{c}\text { Female } \\
\text { Study 3 }\end{array}$ & 9 & 27.8 & 6.5 & 58.2 & 8.7 & 3.20 & 0.58 \\
$\begin{array}{c}\text { Male } \\
\text { Mean }\end{array}$ & 15 & 23.1 & 3.5 & 72.0 & 6.6 & 4.97 & 0.57 \\
\hline
\end{tabular}

Means \pm SD $(=$ Standard deviation)

Cycle speed $\left(\mathrm{km} \mathrm{h}^{-1}\right)=a\left(\dot{\mathrm{V}}_{\mathrm{O}_{2} \max }\right)^{k_{1}}(m)^{k_{2}} \varepsilon$

where ' $a$ ' is a constant and ' $k_{1}$ ' and ' $k_{2}$ ' are the exponents likely to provide the best predictor of cycling speed and ' $\epsilon$ ' is the multiplicative error ratio. The model can be linearized with a log-transformation, and multiple linear regression can be used to estimate unknown parameters $a, k_{1}$ and $k_{2}$. The log-transformed model becomes,

$$
\begin{aligned}
\log _{\mathrm{e}}(\text { speed })= & \log _{\mathrm{e}}(a)+k_{1} \log _{\mathrm{e}}\left(\dot{\mathrm{V}}_{\mathrm{O}_{2} \max }\right)+k_{2} \log _{\mathrm{e}}(m) \\
& +\log _{\mathrm{e}}(\varepsilon) .
\end{aligned}
$$

Note that the parameter ' $a$ ' can be allowed to vary between groups (e.g. sex, men versus women; cycling performance level, national versus club), thus conducting a form of analysis of covariance (ANCOVA). Indeed, additional covariates, such as age, can be added to the model to identify further determinants (continuous variables) of cycling performance.

\section{Results}

\section{Study 1}

The power function model relating cycle speed $\left(\mathrm{km} \mathrm{h}^{-1}\right)$ to maximum oxygen uptake $\dot{\mathrm{V}}_{\mathrm{O}_{2} \max }\left(1 \mathrm{~min}^{-1}\right)$ and body mass, $m(\mathrm{~kg})$, was found to be the same for all five timetrial events (the ANCOVA analysis found no differences in the constant parameter ' $a$ ' having controlled for differences in $\dot{\mathrm{V}}_{\mathrm{O}_{2} \max }\left(1 \mathrm{~min}^{-1}\right)$ and body mass, $\left.m(\mathrm{~kg})\right)$,

Cycle speed $\left(\mathrm{km} \mathrm{h}^{-1}\right)=43.85\left(\dot{\mathrm{V}}_{\mathrm{O}_{2} \max }\right)^{0.45}(m)^{-0.18}$,

with $\left(k_{1}=0.45, \mathrm{SEE}=0.12\right.$, and $\left.k_{2}=-0.18 \mathrm{SEE}=0.13\right)$, $R^{2}=42.3 \%$ and the error ratio, $s=0.063$ or $6.46 \%$, having taken antilogs. The model predicts the mean cycle speed for the time trials $=38.6 \mathrm{~km} \mathrm{~h}^{-1}$ (predicted for an average subject whose $\dot{\mathrm{V}}_{\mathrm{O}_{2} \max }=4.251 \mathrm{~min}^{-1}$ and body mass $=77.5 \mathrm{~kg}$ ).

\section{Study 2}

The power function model for study 2 was given by

Cycle speed $\left(\mathrm{km} \mathrm{h}^{-1}\right)=38.7\left(\dot{\mathrm{V}}_{\mathrm{O}_{2} \max }\right)^{0.38}(m)^{-0.14}$ with $\left(k_{1}=0.38, \mathrm{SEE}=0.08\right.$, and $\left.k_{2}=-0.14 \mathrm{SEE}=0.09\right)$, $R^{2}=85.9 \%$ and the error ratio, $s=0.040$ or $4.08 \%$, having taken antilogs. The analysis found a significant effect of wind direction (head/tail versus side wind) $(P=0.002)$ with the mean cycle speed with a head/tail wind being $5 \%$ slower compared with cyclists performing with a side wind $\left(37.1 \mathrm{~km} \mathrm{~h}^{-1}\right.$ vs $39.1 \mathrm{~km} \mathrm{~h}^{-1}$, respectively, predicted for an average subject whose $\dot{\mathrm{V}}_{\mathrm{O}_{2} \max }=4.431 \mathrm{~min}^{-1}$ and body mass $=69.5 \mathrm{~kg}$ ).

\section{Study 3}

A similar power function model relating cycle speed $\left(\mathrm{km} \mathrm{h}^{-1}\right)$ to maximum oxygen uptake $\dot{\mathrm{V}}_{\mathrm{O}_{2} \max }\left(1 \mathrm{~min}^{-1}\right)$ and body mass, $m(\mathrm{~kg})$ was found in study 3 , given by

Cycle speed $\left(\mathrm{km} \mathrm{h}^{-1}\right)=39.2\left(\dot{\mathrm{V}}_{\mathrm{O}_{2} \max }\right)^{0.51}(m)^{-0.17}$,

with $\left(k_{1}=0.51, \mathrm{SEE}=0.15\right.$, and $\left.k_{2}=-0.17 \mathrm{SEE}=0.13\right)$, $R^{2}=89.0 \%$ and the error ratio, $s=0.024$ or $2.43 \%$, having taken antilogs. The analysis found a significant difference between the two levels of cycling standards (national elite $44.2 \mathrm{~km} \mathrm{~h}^{-1}$ vs state $40.5 \mathrm{~km} \mathrm{~h}^{-1}$; $P<0.001)$ predicted for an average subject whose $\dot{\mathrm{V}}_{\mathrm{O}_{2} \max }=4.951 \mathrm{~min}^{-1}$ and body mass $=71.7 \mathrm{~kg}$. Note that the explained variance of the above model $(89 \%)$ compares very favourably with the explained variance of the best correlate reported by Coyle et al. (1991) i.e. when cycling performance time was correlated with average power $\left(\mathrm{R}^{2}=78 \%\right)$ recorded during a $1-\mathrm{h}$ laboratory performance test.

Studies 1, 2, and 3 combined

The power-function model parameters for the three studies are summarized in Table 2. Given the similarity of the power function models but recognising that differences in cycling speeds (between and within each study) need to be incorporated, the data from the three studies were combined into a single power function ANCOVA.

There were no significant interactions between 'study' and either covariates $\log _{\mathrm{e}}\left(\dot{\mathrm{V}}_{\mathrm{O}_{2} \max }\right)$ and $\log _{\mathrm{e}}(m)$. However, a significant difference in fitted constants between studies was identified $(P<0.001)$. Hence, the common power function model covariates for all three studies relating 
Table 2 The power-function model parameters for studies 1, 2 and 3 Constant $\quad$ SEE $\quad \dot{\mathrm{V}}_{\mathrm{O}_{2} \max }\left(k_{1}\right) \quad$ SEE $\quad$ Mass $\left(k_{2}\right) \quad$ SEE (a)

\begin{tabular}{lllllll}
\hline Study 1 & 43.85 & 1.64 & 0.45 & 0.12 & -0.18 & 0.13 \\
Study 2 & 38.72 & 1.36 & 0.38 & 0.08 & -0.14 & 0.09 \\
Study 3 & 39.18 & 1.47 & 0.51 & 0.15 & -0.17 & 0.13 \\
\hline
\end{tabular}

$S E E$ standard error of estimate

cycle speed $\left(\mathrm{km} \mathrm{h}^{-1}\right)$ to maximum oxygen uptake $\dot{\mathrm{V}}_{\mathrm{O}_{2} \max } 1 \mathrm{~min}^{-1}$ and body mass, $m(\mathrm{~kg})$ was found to be,

Cycle speed $\left(\mathrm{kmh}^{-1}\right)=36.1\left(\dot{\mathrm{V}}_{\mathrm{O}_{2} \max }\right)^{0.41}(m)^{-0.13}$,

with $\quad\left(k_{1}=0 . \quad 41, \quad \mathrm{SEE}=0.061, \quad\right.$ and $\quad k_{2}=-0.13$ $\mathrm{SEE}=0.064), R^{2}=82.1 \%$ and the error ratio, $s=0.046$ or $4.7 \%$, having taken antilogs. Note that the above cycling-speed model can be expressed as $\left(\dot{\mathrm{V}}_{\mathrm{O}_{2} \max }\right)^{0.41}(m)^{-0.13}=\left(\dot{\mathrm{V}}_{\mathrm{O}_{2} \max }(m)^{-0.32}\right)^{0.41}$. All the significant effects observed within the separate analyses (Studies 1,2 and 3) were also detected in the combined analysis. For example, the effect of a side wind was significantly beneficial ( $4.9 \%$ greater) compared with the head/tail wind $\left(41.4\right.$ vs $39.5 \mathrm{~km} \mathrm{~h}^{-1}$, respectively, $P=0.008$ ) having adjusted for differences in the covariates $\dot{\mathrm{V}}_{\mathrm{O}_{2} \max }$ and body mass for an average cyclist whose $\dot{\mathrm{V}}_{\mathrm{O}_{2} \max }$ and body mass was $4.471 \mathrm{~min}^{-1}$ and $72.2 \mathrm{~kg}$, respectively. There was also a significant effect of level, with the elite/national level cyclists riding $11 \%$ faster than the state/club level cyclists (42.6 vs $38.4 \mathrm{~km} \mathrm{~h}^{-1}$ ), having adjusted for differences in the covariates $\dot{\mathrm{V}}_{\mathrm{O}_{2} \max }$ and body mass. As described above, due to the different courses for each study, not surprisingly there was a significant main effect on cycling speed due to 'Study', as seen in Fig. 1.

\section{Discussion}

There was a remarkable similarity in power function covariates from Studies 1, 2 and 3 (see Table 2). Although differences in cycling speed between and within each study were anticipated due to the variation in the resistive forces between time-trial events (Martin et al. 1998; Jeukendrup and Martin 2001), the combined ANCOVA was able to accommodate all these differences by allowing the constant $\log _{\mathrm{e}}(a)$ (Eq. 1) to vary for these known effects, resulting in the common powerfunction covariates, $\left(\dot{\mathrm{V}}_{\mathrm{O}_{2} \max }(m)^{-0.32}\right)^{0.41}$, given in Eq. 2 . Since there were no statistically significant differences between model covariates for each of the Studies 1, 2 and 3 , the common proportional model would appear to be robust in describing the relationship between maximum oxygen uptake and body mass when predicting time-trial cycling performance on level ground. Given the broad range of variables (topographical, environmental and aerodynamic) known to contribute to timetrial cycling, this consistency provides considerable support for the proposed scaling methods and model.

The maximum oxygen uptake-to-mass ratio, $\dot{\mathrm{V}}_{\mathrm{O}_{2} \max }(m)^{-0.32}$, would appear to be precisely the same as that originally derived by Swain (1994), theoretically supported by Heil (2001) and effectively utilised by Padilla et al. (1999). The energy cost of having greater body mass (on relatively flat time-trial courses) would appear to be the same for both sub-maximal and maximal speeds. The assumption that the mass exponent associated with frontal drag of cyclists riding in the tuck position was confirmed as approximately $\mathrm{m}^{1 / 3}$, considerably less than the body-mass surface area $\left(\mathrm{m}^{2 / 3}\right)$ assumed on theoretical grounds.

However, the power-function model was also able to confirm a proportional curvilinear association between cycling speed and energy cost, given by $\left(\dot{\mathrm{V}}_{\mathrm{O}_{2} \max }(m)^{-0.32}\right)^{0.41}$. Although Pugh (1974) had fitted a polynomial regression model, no details of the model were provided. Unfortunately, polynomial regression models are invariably fitted for mathematical convenience rather than biological expediency. For example, polynomial models will routinely incorporate an intercept term that would, in this case, predict a positive (or negative) speed for a cyclist with zero $\dot{\mathrm{V}}_{\mathrm{O}_{2} \max }$. The proportional power-function model $\left(\dot{\mathrm{V}}_{\mathrm{O}_{2} \max }(m)^{-0.32}\right)^{0.41}$, would suffer no such limitation.
Fig. 1 The cycling speed power-function models $\left(\dot{\mathrm{V}}_{\mathrm{O}_{2} \max }(m)^{-0.32}\right)^{0.41}$ for studies 1,2 and 3 (predicted for male club-standard cyclists with a head/tail wind, whose $\dot{\mathrm{V}}_{\mathrm{O}_{2} \max }=4.471 \mathrm{~min}^{-1}$ and mass $=72.2 \mathrm{~kg}$ )

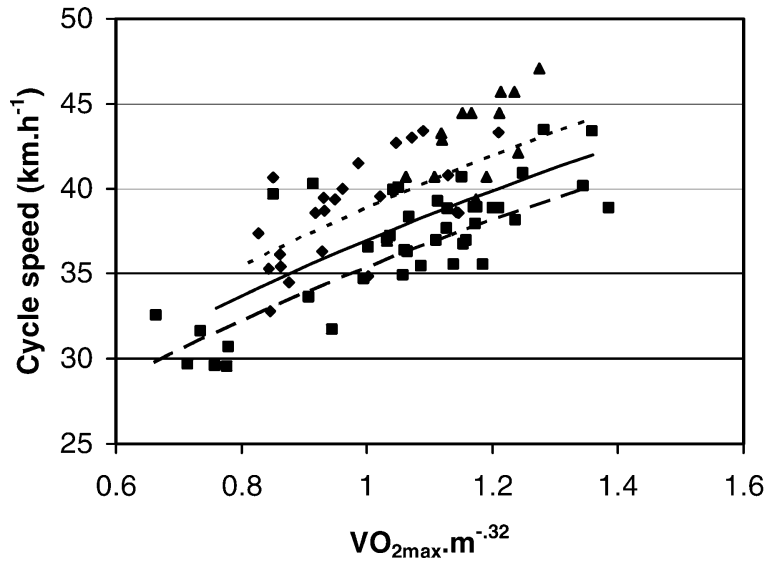


A cyclist expends energy to overcome air resistance known to increase in proportion to the square of speed Swain et al. (1987). Put another way, the speed of a cyclist will be constrained by air resistance known to be proportional to the square root of the energy expended. We might speculate that the fitted power-function exponent $0.41(\mathrm{SEE}=0.061)$ being a little less than the square root $(0.5)$, might be due to the additional drag required to overcome the cyclists' rolling resistance as well as air resistance. Given the fact that the energy cost of running is known to be a linear function of maximum oxygen uptake $\left(\mathrm{ml} \mathrm{kg}^{-1} \mathrm{~min}^{-1}\right)$, we can speculate that the observed curvilinear association between cycling speed and energy cost is due to cyclists riding at much greater range of speeds than runners where air resistance begins to have a proportionally greater influence on limiting their performance.

The model has practical advantage for the sports scientist. Given a cyclist's $\dot{\mathrm{V}}_{\mathrm{O}_{2} \max }$ and body mass together with details of a time-trial distance (either 25 miles, $26 \mathrm{~km}$ or $40 \mathrm{~km}$ for studies 1,2 and 3 , respectively), we can use the models from studies 1,2 and 3 to predict the cyclists' average time-trial cycling speed directly. To appreciate the value of fitting the proposed curvilinear power-function model, consider the following hypothetical example. Suppose a male cyclist (mass $=72.2 \mathrm{~kg}$ ) wishes to increase his mean timetrial speed from $30 \mathrm{~km} \mathrm{~h}^{-1}$ to $35 \mathrm{~km} \mathrm{~h}^{-1}$, the model predicts that he would need to increase his $\dot{\mathrm{V}}_{\mathrm{O}_{2} \max }$ from $2.361 \mathrm{~min}^{-1}$ to $3.441 \mathrm{~min}^{-1}$, an increase of $1.081 \mathrm{~min}^{-1}$. For another male cyclist of the same mass to increase his mean speed from $40 \mathrm{~km} \mathrm{~h}^{-1}$ to $45 \mathrm{~km} \mathrm{~h}^{-1}$, he would require to increase his $\dot{\mathrm{V}}_{\mathrm{O}_{2} \max }$ from $4.771 \mathrm{~min}^{-1}$ to $6.361 \mathrm{~min}^{-1}$, i.e. a much greater increase in $\dot{\mathrm{V}}_{\mathrm{O}_{2} \max }(50 \%$ more $)$ of $1.591 \mathrm{~min}^{-1}$.

Finally, although the power-function ANCOVA model was able to explain $82.1 \%$ of the variance, another advantage of the model is that it allows other possible additional determinants of cycling speed to be assessed/evaluated having already controlled for differences in $\dot{\mathrm{V}}_{\mathrm{O}_{2} \max }$ and body mass. For example, when the subjects' age was added to the model as a possible additional covariate, no significant additional variance in cycling speed was explained. However, when we incorporated the variable 'wind direction' into the model (side versus head/tail wind), we identified the significant benefit of cycling with a side wind $(5 \%$ faster $)$ $(P=0.008)$. We acknowledge that the effect of wind speed as well as wind direction could improve our understanding of cycling performance. However, since details of wind speed and direction were not available in two of the three studies, we incorporated wind direction predominatly as an example of how the effect of an additional factor can be added to our model when pre- dicting time-trial cycling performance. Simply by adding or modifying variables in the ANCOVA model (either as categorical factors or continuous covariates), future research could explore whether the same scaling approach could be applied to, for example, alternative measures of recording power output to improve the prediction of time-trial cycling performance.

\section{References}

Box GEP, Cox DR (1964) An analysis of transformations (with Discussion). J Roy Stat Soc Ser B 26:211-252

Coyle EF, Feltner ME, Kautz SA, Hamilton MT, Montain SJ, Baylor AM, Abraham LD, Petrek GW (1991) Physiological and biomechanical factors associated with elite endurance cycling performance. Med Sci Sports Exerc 23:93-107

Dill DB (1965) Oxygen use in horizontal and grade walking and running on the treadmill. J Appl Physiol 20:19-22

Heil DP (2001) Body mass scaling of projected frontal area in competitive cyclists. Eur J Appl Physiol 85:358-366

Ingham SA, Whyte GP, Jones K, Nevill AM (2002) Determinants of $2,000 \mathrm{~m}$ rowing ergometer performance in elite rowers. Eur J Appl Physiol 88:243-246

ISAK (2001) International standards for anthropometric assessment. ISAK, Underdale, South Australia

Jeukendrup AE, Martin J (2001) Improving cycling performance: how should we spend our time and money. Sports Med 31:559569

Keen PS, Passfield L, Hale T (1991) Indirect determination of VO2max using a sports-specific (cycling) ergometry system. J Sports Sci 9:420

Margaria R, Cerretelli P, Aghemo P, Sassi G (1963) Energy cost of running. J Appl Physiol 18:367-370

Martin JC, Milliken DL, Cobb JE, McFadden KL, Coggan AR (1998) Validataion of a mathematical model for road cycling power. J Appl Biomech 14:276-291

McCole SD, Claney K, Conte JC, Anderson R, Hagberg JM (1990) Energy expenditure during bicycling. J Appl Physiol 68:748-753

Nevill AM, Ramsbottom R, Williams C (1992) Scaling physiological measurements for individuals of different body size. Eur J Appl Physiol Occup Physiol 65:110-117

Nevill A, Rowland T, Goff D, Martel L, Ferrone L (2004) Scaling or normalising maximum oxygen uptake to predict 1-mile run time in boys. Eur J Appl Physiol 92:285-288

Olds TS, Norton KI, Lowe ELA, Olive S, Reay F, Ly S (1995) Modeling road-cycling performance. J Appl Physiol 78:15961611

Padilla S, Mujika I, Cuesta G, Goiriena JJ (1999) Level ground and uphill cycling ability in professional road cycling. Med Sci Sports Exerc 31:878-885

Palmer GS, Dennis SC, Noakes TD, Hawley JA (1996) Assessment of the reproducibility of performance testing on an air-braked cycle ergometer. Int J Sports Med 17:293-298

Pugh LGCE (1974) The relation of oxygen intake and speed in competition cycling and comparative observations on the bicycle ergometer. J Physiol Lond 241:795-808

RTTC (2004) Handbook. Geerings, Ashford

Swain DP (1994) The influence of body-mass in endurance bicycling. Med Sci Sports Exerc 26:58-63

Swain DP, Coast JR, Clifford PS, Milliken MC, Straygundersen J (1987) Influence of body size on oxygen-consumption during bicycling. J Appl Physiol 62:668-672 